\title{
Spatial, Temporal, and Human-Induced Variations in Suspended Sediment Concentration in the Surface Waters of the Yangtze Estuary and Adjacent Coastal Areas
}

\author{
P. Li • S. L. Yang • J. D. Milliman • K. H. Xu • \\ W. H. Qin • C. S. Wu • Y. P. Chen • B. W. Shi
}

Received: 26 July 2011 /Revised: 24 February 2012 / Accepted: 24 February 2012 /Published online: 28 June 2012

(C) The Author(s) 2012. This article is published with open access at Springerlink.com

\begin{abstract}
To delineate temporal and spatial variations in suspended sediment concentration (SSC) in the Yangtze (Changjiang) Estuary and adjacent coastal waters, surfacewater samples were taken twice daily from 10 stations over periods ranging from 2 to 12 years (total number of samples $>28,000)$. Synoptic measurements in 2009 showed an increase in surface SSC from $0.058 \mathrm{~g} / 1$ in the upper sections of the estuary to $\sim 0.6 \mathrm{~g} / \mathrm{l}$ at the Yangtze River turbidity maximum at the river mouth, decreasing seaward to $0.057 \mathrm{~g} / \mathrm{l}$. Annual periodicities reflect variations in the Yangtze discharge, which affect the horizontal distribution and transport of SSC, and seasonal winds, which result in vertical resuspension and mixing. Over the past 10-20 years, annual surface SSC in the lower Yangtze River and the upper estuary has decreased by $55 \%$, due mainly to dam construction in the
\end{abstract}

Electronic supplementary material The online version of this article (doi:10.1007/s12237-012-9523-x) contains supplementary material, which is available to authorized users.

P. Li $\cdot$ S. L. Yang $(\bowtie) \cdot$ C. S. Wu $\cdot$ Y. P. Chen $\cdot$ B. W. Shi

State Key Lab of Estuarine and Coastal Research,

East China Normal University,

Shanghai 200062, China

e-mail: slyang@sklec.ecnu.edu.cn

P. Li • W. H. Qin

East China Sea Centre of Standard and Metrology,

State Oceanic Administration of China,

Shanghai 201306, China

J. D. Milliman

School of Marine Science, Virginia Institute of Marine Science,

College of William \& Mary,

Gloucester Point, VA 23062, USA

K. H. Xu

Department of Marine Science, Coastal Carolina University,

P.O. Box 261954, Conway, SC 29528, USA upper and middle reaches of the river. The $20-30 \%$ decrease in mean surface SSC in the lower estuary and adjacent coastal waters over the same period presumably reflects sediment resuspension, in part due to erosion of the subaqueous Yangtze Delta. SSCs in the estuary and adjacent coastal waters are expected to continue to decline as new dams are constructed in the Yangtze basin and as erosion of the subaqueous delta slows in coming decades.

Keywords Suspended sediment concentration - Three Gorges Dam (TGD) · Yangtze (Changjiang) estuary · Hangzhou bay $\cdot$ Turbidity maximum $\cdot$ Periodicity

\section{Introduction}

Suspended sediment concentration (SSC) plays a key role in determining the ecology, geomorphology and water quality in estuarine and coastal waters (e.g., El-Asmar and White 2002; Zheng et al. 2004; Schoellhamer et al. 2007 and references therein). Due to the collective impacts of river discharge, tides, wind-driven waves, and currents, SSC also tends to be highly variable in most coastal areas (e.g., Yang et al. 2004; Uncle and Stephens 2010 and references therein). Although numerous studies have focused on SSC in estuarine and coastal waters (e.g., Singh et al. 2007 and those cited above), few have focused on long-term spatial or temporal variations even though accelerating by anthropogenic activities and their impacts increasingly necessitate such monitoring.

In this paper, we focus on the Yangtze River (Fig. 1), one of the largest rivers in the world, third in length $(6,300 \mathrm{~km})$, fourth in sediment load (until recently $>400$ million tons per year-Mt/year), and fifth in water discharge $\left(\sim 900 \mathrm{~km}^{3} /\right.$ year $)$ (Zhao et al. 2000; Milliman et al. 2010). More than 98\% of the sediment discharge from the Yangtze is suspended load 
Fig. 1 Maps of the study area, showing a the Yangtze River Basin and $\mathbf{b}$ the locations of gauging stations used for measurements of suspended sediment concentrations in the Yangtze Estuary and adjacent waters. Note the locations of the longshore and cross-shore transects in (b)
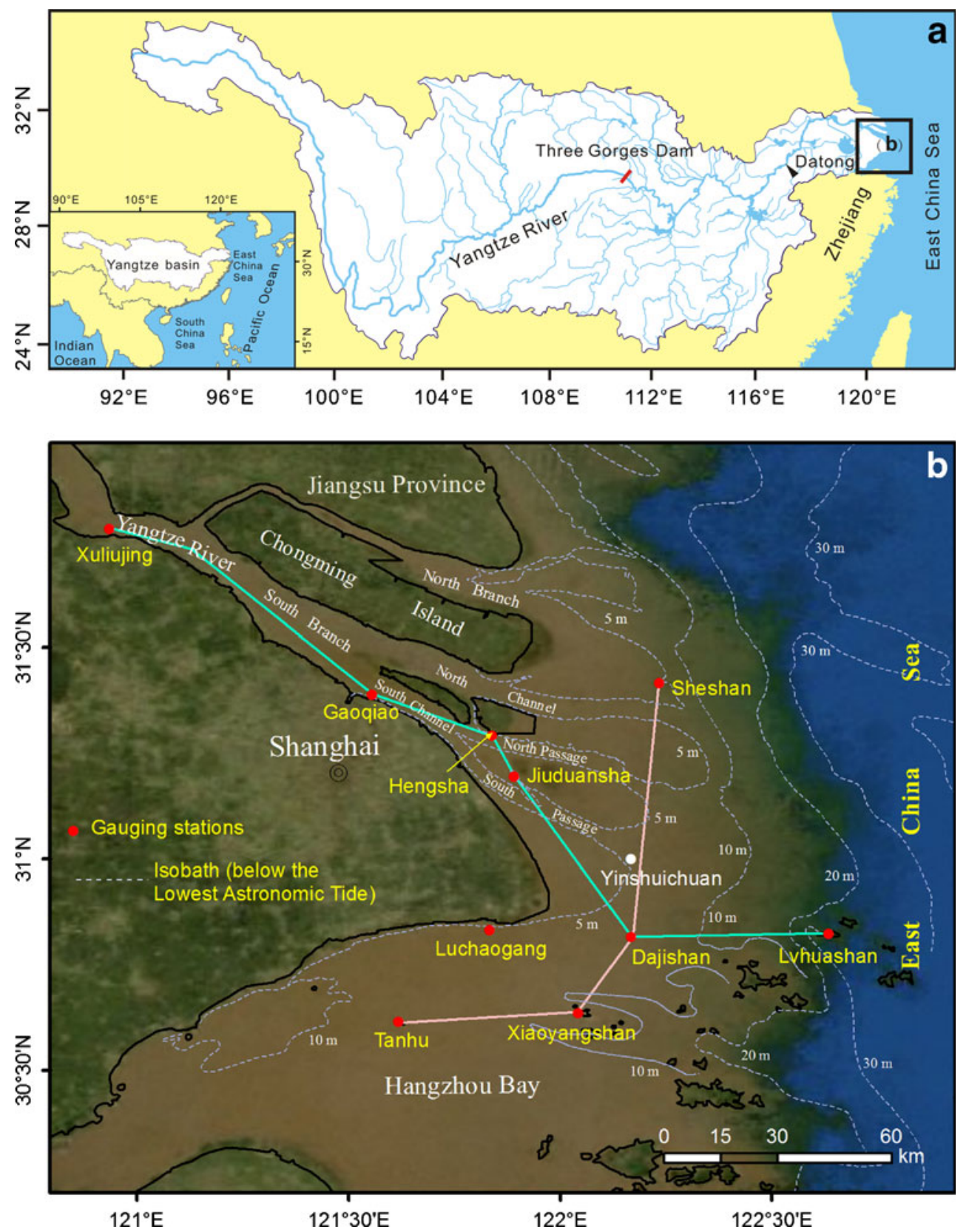

(Yang et al. 2003). The bulk of the Yangtze's fresh water, sediment, and nutrients is discharged to the East China Sea (Yang et al. 2010), resulting in one of the world's largest coastal fisheries and one of the world's largest deltaic cities, Shanghai, current population exceeding 20 million people.

Yangtze discharge is highly seasonal, reflecting the strong monsoonal influence in precipitation ( $\mathrm{Xu}$ and Milliman 2009). Peak discharge occurs during the summer monsoon, when water and sediment discharge historically (1950-2002) have averaged 3.6 and 19.3 times, respectively, those during the winter monsoon. Since closure of the Three Gorges Dam (TGD), these seasonal differences have declined to 3.1 and 8.7 (2003-2009), respectively (Fig. 2).
Yearly-averaged salinity of surface water ranges from 0.21 at Xuliujing, the upstream limit of the estuary, to 27.1 at Lvhuashan, the seaward-most station of this study (Fig. 3).

A second defining parameter of the Yangtze Estuary and adjacent waters is its macrotidal (Fig. 3) semidiurnal tides, varying from 2 (neap tide) to $4 \mathrm{~m}$ (spring tide) in range. Within the estuary, tidal range is highest at the mouth bar area at the middle North and South Passages and in the lower North Channel (Fig. 3). Intertidal and spring-neap flows are highly variable, with peak velocities of $\sim 2 \mathrm{~m} / \mathrm{s}$ in the Yangtze Estuary and $\sim 2.5 \mathrm{~m} / \mathrm{s}$ in the Hangzhou Bay (GSCCI 1988). During spring tides the estuarine water is well-mixed and with higher SSC compared to partly 
Fig. 2 Seasonal changes in water discharge (a) and sediment load (b) at Datong (based on data from the Water Conservancy Committee of the Yangtze River, Ministry of Water Conservancy of China)
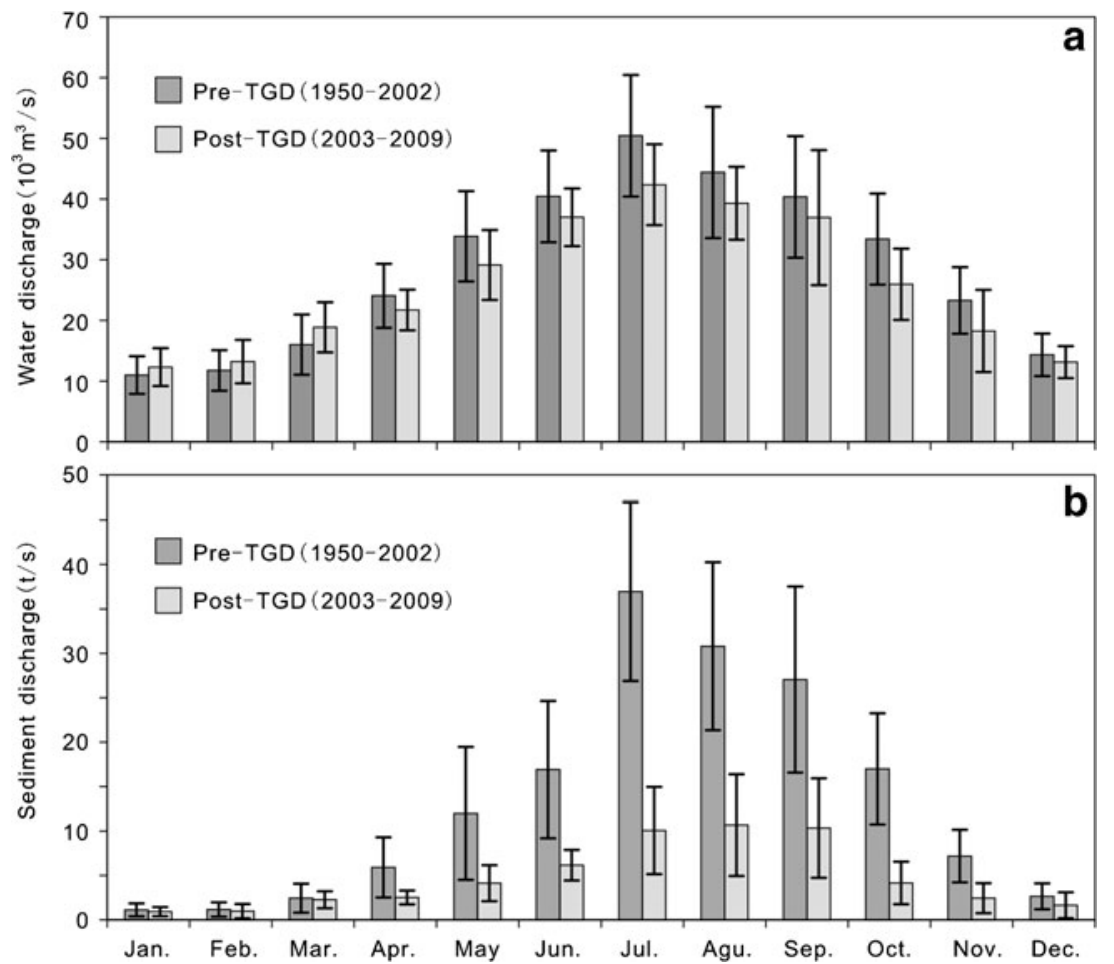

stratified waters (and thus with lower surface salinities) and lower SSC during neap tides (Milliman et al. 1984, 1985). One result of the macrotidal influence is that tides extend $\sim 600 \mathrm{~km}$ upstream, making Datong Station, just upstream from the tidal limit, the Yangtze's seaward-most gauging station for water discharge and suspended sediment measurements. More than $95 \%$ of the river's water and sediment is discharged through the three outlets of the South Branch (Chen et al. 1985).

As a result of seasonal cooling, more energetic winds, and lower river discharge, Yangtze waters tend to be better mixed in winter than in summer. Wave heights, however,

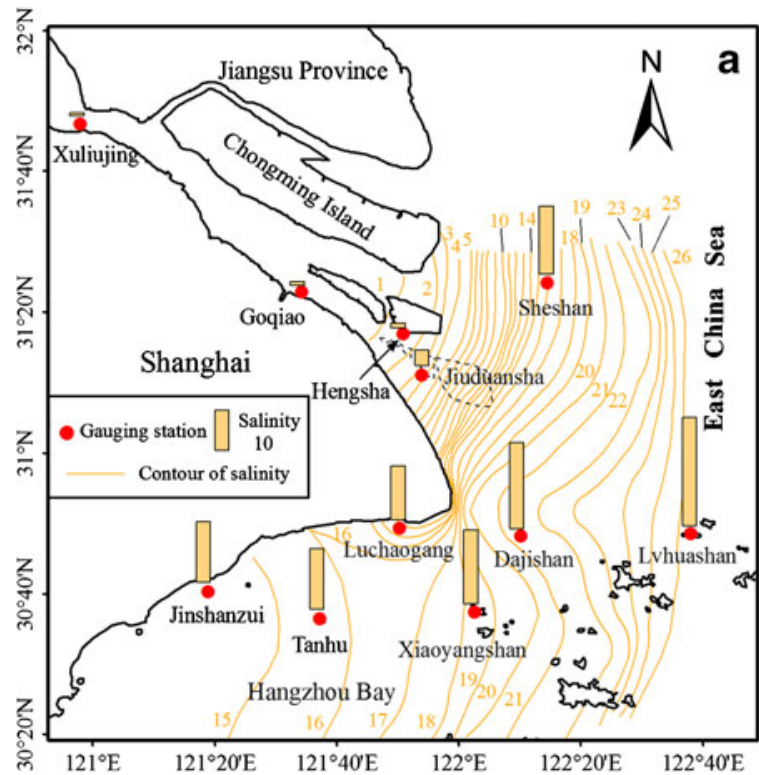

Fig. 3 Annually averaged surface salinity (a) and tidal range (b) at gauging stations. Contours show interpolated surface salinity (a) and tidal range (b) in areas between the gauging stations. All the averages are based on data for 2009 (i.e., an observation period of 365 days).

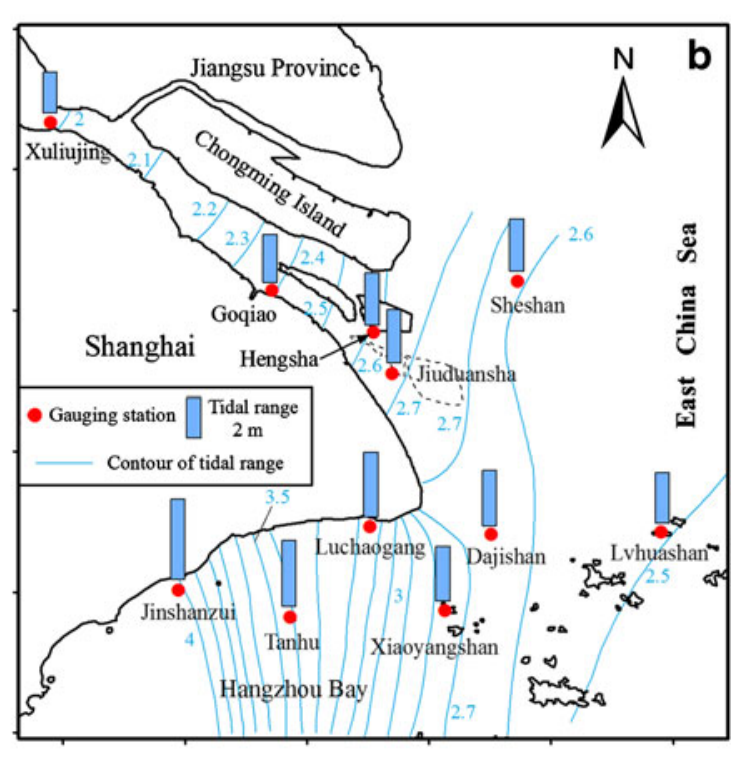

The frequency of observations was twice daily except for Luchaogang station (daily). The frequency of tide observations was 288 per day (i.e., 5-min intervals). The tide data were sourced from the East China Sea Forecast Centre, State Oceanic Administration of China 
vary considerably depending on location: multi-year wave heights average $0.2 \mathrm{~m}$ in the inner estuary (at Gaoqiao, Fig. 1), $1.0 \mathrm{~m}$ in the southern portion of the outer estuary (near Dajishan) (GSCCI 1988), and $0.5 \mathrm{~m}$ in inner Hangzhou Bay (at Tanhu) (unpublished data from East China Sea Forecast Centre, State Oceanic Administration of China).

Of particular relevance to the discharge and SSC of the Yangtze River is the impact of the more than 50,000 dams in its watershed, the most notable example being the TGD, $1,800 \mathrm{~km}$ upstream from the estuary, which was closed in June 2003 (Fig. 1a) (e.g., Yang et al. 2007; Hu et al. 2009). In response to the increased damming of the river and the corresponding decreased sediment load, the Yangtze subaqueous delta is now eroding as much as $100,000,000 \mathrm{~m}^{3} /$ year (Yang et al. 2011). In this context, temporal and spatial variations of SSC in the Yangtze River, its estuary, and adjacent coastal waters become increasingly more complicated.

Previous studies on SSC in the Yangtze Estuary have focused on intertidal, spring-neap, and seasonal and vertical changes (e.g., Milliman et al. 1985; Chen et al. 2006); for the most part, however, these studies have lacked temporal or spatial perspectives. For example, the Chen et al. (2006) study of surface SSC variations in the Yangtze Estuary and northern Hangzhou Bay relied on data from eight gauging stations, but measured in different years; moreover, the absence of a gauging station seaward of the mouth bar prevented Chen et al. (2006) from documenting any seaward trend in SSC.

In this study, we address spatial and temporal variations in SSC in the surface waters of Yangtze estuary and adjacent coastal waters based on multiple-year samplings at 10 sites. These data allow us to (1) define cross-shore and longshore variations in SSC, (2) delineate factors controlling SSC periodicity, and (3) examine the SSC response to the decline in suspended sediment supply from the Yangtze River, particularly after closure of the TGD. In this respect, the Yangtze may be unique in that oceanographic measurements were taken both before and after the 2003 closure of the TGD.

\section{Materials and Methods}

Surface water was sampled with $600-\mathrm{ml}$ bottles at nine stations in the Yangtze estuary and surrounding waters (Fig. 1b) twice daily, generally $8 \mathrm{AM}$ and $2 \mathrm{PM}$, between 1998 and 2009, and daily at Luchaogang at high tides between June 2002 and May 2010 (Table 1). This sampling arrangement allowed us to define SSC variations along both cross-shore and along-shore transects (Fig. 1b). Two stations, Gaoqiao in the South Channel and Jiuduansha in the South Passage, were sampled only in 2009, whereas the other eight stations are represented by 4 years or more of data, with Luchaogang and Xiaoyangshan, both in northern Hangzhou Bay, being sampled for 8 and 12 years, respectively. In 2009, all 10 stations were sampled (Table 1). The dataset, representing more than 28,000 samples, thus allows us to delineate surface SSC variations spatially, temporally, and quasi-synoptically.

Most water samples were filtered through pre-weighed $0.45-\mu \mathrm{m}$ filters, which were then rinsed and dried at $45^{\circ} \mathrm{C}$ for $48 \mathrm{~h}$, and then weighed. SSC was calculated as the ratio of suspended sediment weight to water volume filtered. We analyzed only 20 samples (collected at the Luchaogang Station in July 2003; SSC ranging from 0.2 to $1.4 \mathrm{~g} / \mathrm{l}$ ) for particulate carbon, both calcium carbonate and organic matter. These samples were treated with hydrochloric acid (30\%) to remove carbonate, dried at $45^{\circ} \mathrm{C}$ for $48 \mathrm{~h}$, and then combusted at $950^{\circ} \mathrm{C}$. This treatment removed only $0.3 \%$ to $0.6 \%$ of the SSC. Given the very low particulate

Table 1 Information on observation stations and suspended sediment concentration (SSC) data

\begin{tabular}{lllllll}
\hline Station name & Location & $\begin{array}{l}\text { Mean water } \\
\text { depth }(\mathrm{m})\end{array}$ & $\begin{array}{l}\text { Years of hydrological } \\
\text { observations }\end{array}$ & $\begin{array}{l}\text { Frequency } \\
\text { (years) }\end{array}$ & $\begin{array}{l}\text { Duration } \\
\text { observations }\end{array}$ \\
\hline Xuliujing & Yangtze River & 10 & $1999-2000,2008-2009$ & Twice daily & 4 & 2,920 \\
Gaoqiao & South Channel & 10 & 2009 & Twice daily & 1 & 730 \\
Hengsha & North Passage & 8 & $1999-2000,2008-2009$ & Twice daily & 4 & 2,920 \\
Jiuduansha & Mouth bar & 5 & 2009 & Twice daily & 1 & 730 \\
Dajishan & Southern coastal water off YE & 9 & $1999-2000,2008-2009$ & Twice daily & 4 & 2,920 \\
Lvhuashan & Offshore margin of Yangtze delta & 30 & $2008-2009$ & Twice daily & 2 & 1,460 \\
Sheshan & Northern coastal water off YE & 7 & $1999-2000,2008-2009$ & Twice daily & 4 & 2,190 \\
Xiaoyangshan & Mouth of Hangzhou Bay & 14 & $1998-2009$ & Twice daily & 12 & 8,760 \\
Luchaogang & North coast of Hangzhou Bay & 5 & June 2002-May 2010 & Daily & 8 & 2,922 \\
Tanhu & Central Hangzhou Bay & 11 & $1992-1993,2008-2009$ & Twice daily & 4 \\
\hline
\end{tabular}

The locations of the gauging stations are shown in Fig. 1b

YE Yangtze Estuary 
Fig. 4 a-i Time series of daily suspended sediment concentration and tidal range for 2009 at nine selected stations in the Yangtze Estuary and adjacent waters. Fifteen-day running average of SSC is also shown. Note: the range of the Y-1 axis is from 0.0 to $0.4 \mathrm{~g} / 1$ for stations Xuliujing and Lvhuashan, and from 0.0 to $4.0 \mathrm{~g} / 1$ for the other stations

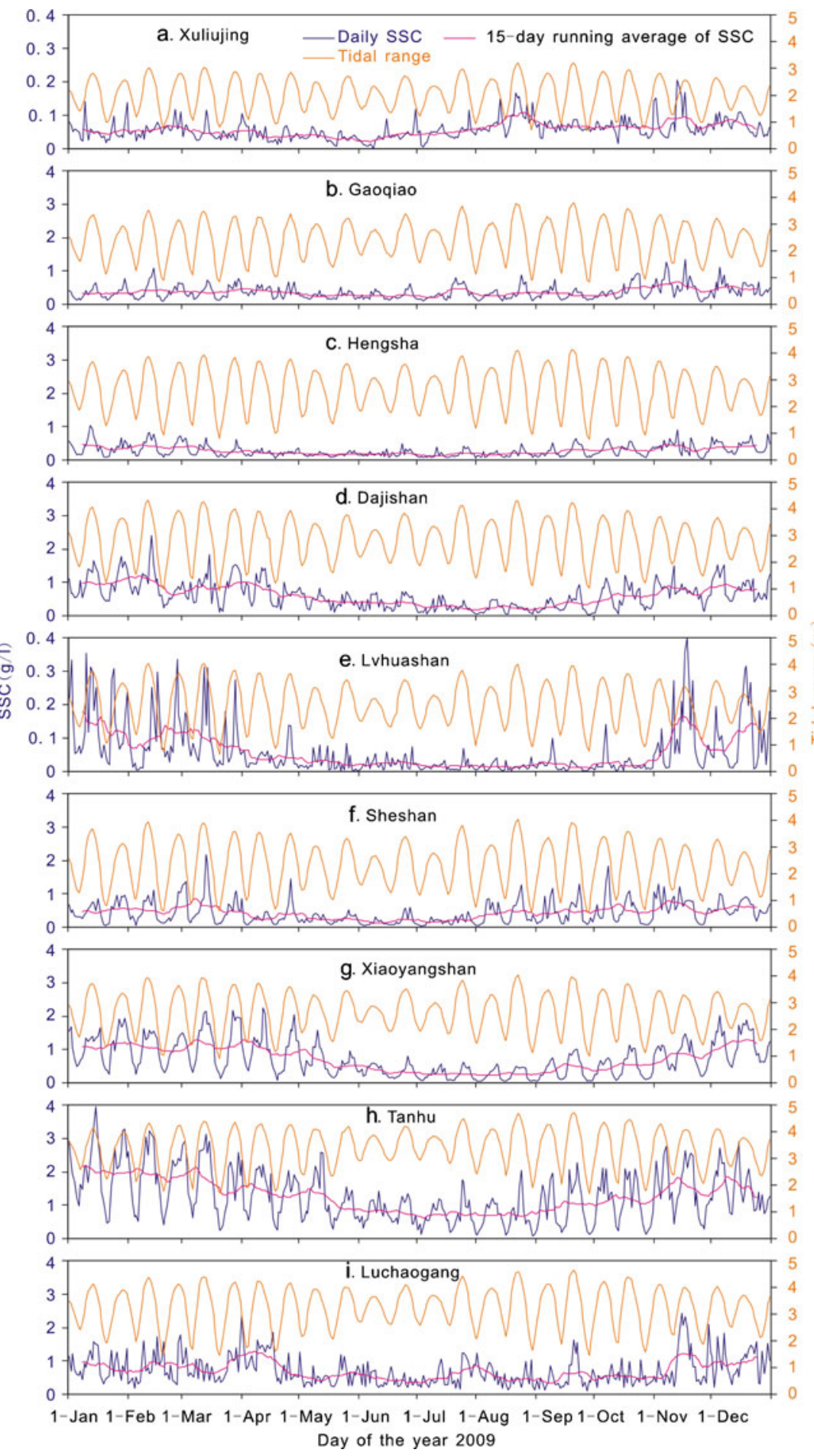

carbon at this ocean-most station and the time-consuming nature of the analyses, we did not measure these parameters further.

Because of the twice-daily or daily sampling procedure, we could not resolve flood vs. ebb tidal variations, but we were able to focus on fortnightly (spring/neap tides) and seasonal variations, assuming that flood-ebb differences in tidal character would be smoothed out over the long term.
Data on water and sediment discharges at the Datong gauging station (see Fig. 1a) were collected from the Yangtze Water Conservancy Committee. Wave, tide, and wind data were furnished by the East China Sea Forecast Centre, State Oceanic Administration of China. The methods of rank-sum test (Hirsch et al. 1992) and Mann-Kendall (MK) test were employed to examine the significance level of the long-term decrease in surface SSC. 


\section{Results and Analyses}

Temporal Variations in SSC during 2009

\section{Spring-Neap Variation}

Daily surface SSC in 2009 was strongly correlated with tidal range, with maxima seen during spring tides and minima during neap tides (Fig. 4). SSCs during spring tides were typically two to three times greater than those during neap tides. Although the SSC at all gauging stations showed a statistically significant $(P<0.001)$ spring-neap signal of 1415 days (Appendix Table 1), there were significant differences among the stations. The regularity of spring-neap cycles of SSC at the Tanhu (Fig. 4h) and Luchaogang (Fig. 4i) stations, both located within Hangzhou Bay, reflects high tidal ranges and greater water depths $(>5 \mathrm{~m})$, which result in greater tidal resuspension and less wavedriven resuspension. In contrast, the spring-neap cycles of SSC were least apparent in the upper estuary at Xuliujing, presumably reflecting the dominance of river discharge over a relatively small tidal range (Fig. 4a). Luchaogang, in northern Hangzhou Bay, also showed a relatively weak spring-neap signal, in this case reflecting its proximity to an exposed mud bank where wave-driven resuspension is particularly strong.

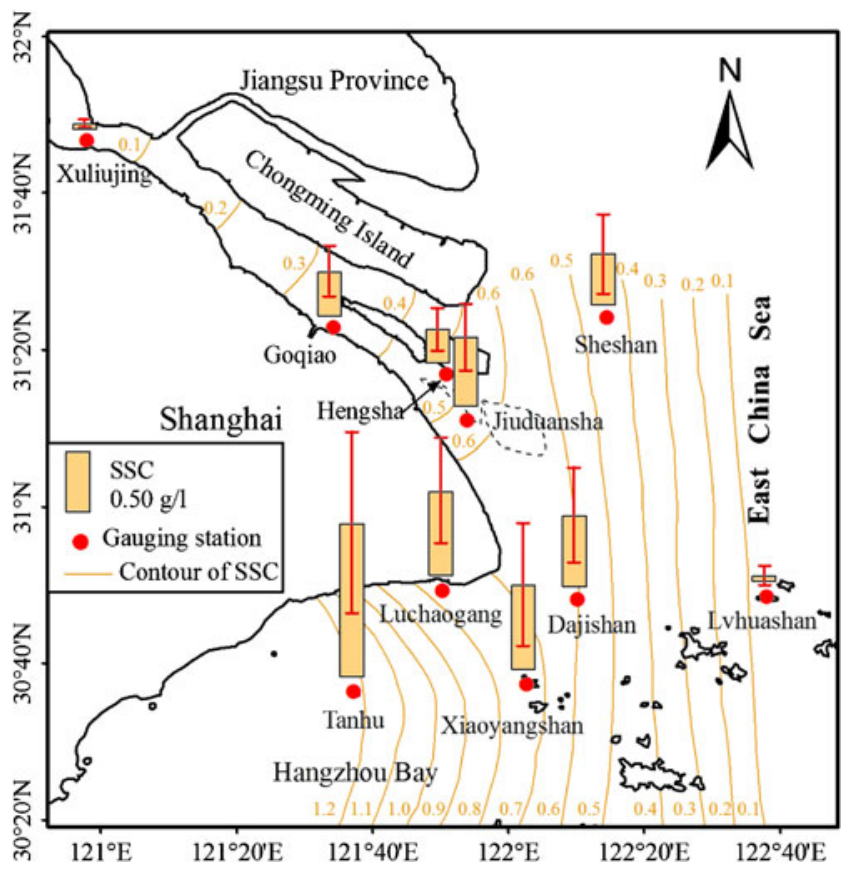

Fig. 5 Averages and standard deviations of surface SSC in the year 2009 at gauging stations. Contours show the average interpolated SSC in areas between the gauging stations. The frequency of observations was twice daily except for Luchaogang station (daily)

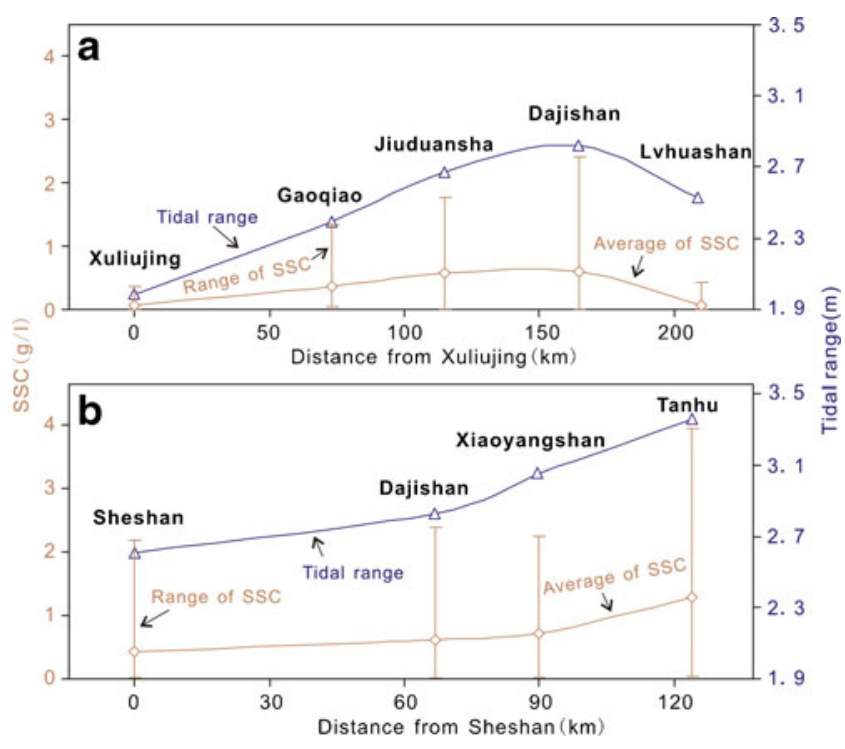

Fig. 6 Cross-shore (a) and longshore (b) variations in suspended sediment concentration and tidal range (based on 2009 data)

\section{Seasonal Variations}

A 15-day running average of SSC was calculated to remove spring-neap cycles and thus to highlight seasonal variations. An annual cyclicity in SSC is apparent in waters adjacent to the Yangtze Estuary, particularly at Sheshan, Lvhuashan, Dajishan, Xiaoyangshan, and Tanhu. At these stations, wintertime SSC was 2.9 to 3.8 times greater than that in summer. At the other sites, SSC was also higher in winter than in summer, although the annual cyclicity was less pronounced (Fig. 4), with the mean SSC being 1.5 to 1.9 times greater in winter than in summer. The spring-neap cyclicity of SSC was weaker in summer than in winter (Fig. 4), reflecting the influence of seasonal variations in the discharge of water and sediment from the Yangtze River. Increased river discharge in summer can result in enhanced stratification and reduced vertical mixing of the water column.

Spatial Pattern of Surface SSC in 2009

Mean surface SSC along the southern channels of the Yangtze Estuary in 2009 increased from $0.058 \mathrm{~g} / \mathrm{l}$ at the landward-most station (Xuliujing) to $0.5-0.6 \mathrm{~g} / \mathrm{l}$ at the river mouth, and then decreased farther offshore to a minimum of $0.057 \mathrm{~g} / 1$ at the seaward-most station, Lvhuashan (Figs. 5 and 6a). The mean SSC on the along-shore transect showed an increase towards Hangzhou Bay, from $0.422 \mathrm{~g} / 1$ at Sheshan to $1.28 \mathrm{~g} / 1$ at Tanhu (Figs. 5 and 6b). Overall, SSC in Hangzhou Bay was much higher than that in the Yangtze estuary. Although minimum surface SSCs at the stations were all $<0.01 \mathrm{~g} / \mathrm{l}$, the range of surface SSC showed similar cross-shore and longshore trends to those of the mean SSC (Fig. 6). 


\section{Longer-Term Variations in SSC}

Over the past 10-20 years, the annual suspended sediment discharge (SSD) and SSC in the lower Yangtze River (at Datong) have decreased by $63 \%$ and $55 \%$, respectively (Table 2). In the estuary and in coastal waters, annual SSC at all gauging stations has decreased following the closure of the TGD by $5-56 \%$ (average $26 \%$ ). The $56 \%$ decrease was found at Xuliujing in the upper estuary; the 5\% decrease was found at Sheshan, on the delta front (Table 2). The decrease in SSC at Sheshan was not statistically significant ( $P>0.05$, rank-sum test), whereas the decreases at the other six stations were significant $(P<0.01)$ (Table 2).

At Xiaoyangshan, where observations of SSC have been conducted since 1998, the annual average of SSC has shown a significant decreasing trend (MK test, $Z=-2.12 ; P=0.009$ ) (Table 3). However, the 3-year running mean of SSC at Xiaoyangshan began to decrease consistently after 2004, 1 year after closure of the TGD (Fig. 7). This time series shows a stronger significant decreasing trend (MK test, $Z=$ $-2.65 ; P=0.002)$ than the annual average (Table 3). Given that a steady decrease in the 3-year running mean of SSD at Datong began in 2000 (Fig. 7), this suggests a 4-year time lag (in terms of SSC) compared with Xiaoyangshan. A linear regression between the annual average of SSC at Xiaoyangshan and the annual SSD at Datong revealed that the correlation coefficient and significance level between these variables were highest for an SSC lag of 4 years for the 3-year-running-mean time series and an SSC lag of 24 years for the annual series (Appendix Table 2).

\section{Discussion}

Spatial Controls on Surface SSC in the Yangtze Estuary

The turbidity maximum off the Yangtze is mainly structured in an onshore-offshore direction like a classic estuarine turbidity maximum. However, the turbidity maximum off the Yangtze also turns strongly to the south along the coast. Although turbidity maxima have been widely studied in various estuaries (e.g., Orton and Kineke 2001; Shi and Kirby 2003 and references therein), the mechanisms leading to their formation are complicated. In the present study, SSC at the Yangtze mouth and Hangzhou Bay was an order of magnitude greater than that at Datong, probably due to strong tidal currents, because the pattern of SSC was strongly related to the tidal range (Fig. 6a, b). In addition, the water depth of the turbidity maximum is $\leq 5 \mathrm{~m}$ in the mouth-bar area of the Yangtze and 5-10 $\mathrm{m}$ in the shallow Hangzhou Bay, much less than the $20-30 \mathrm{~m}$ water depth at the seaward-most station (Fig. 1b). Therefore, local resuspension, driven by strong tidal currents and waves, is probably a key control on the turbidity maximum in the present study area. However, resuspension is unlikely to entirely explain the estuarine turbidity maximum. In addition to resuspension, there must exist a key trapping mechanism that keeps the SSC high near the river mouth rather than being dispersed away from the area of largest tides. The trapping of suspended sediment near the Yangtze mouth and along the shore to the south is likely due to salinity fronts (Fig. 3a) and the structure of regional longshore currents (Liu et al. 2006).

Along the longshore transect, the annual average surface SSC in 2009 increased from $0.422 \mathrm{~g} / 1$ at Sheshan station off the Yangtze mouth to $1.28 \mathrm{~g} / 1$ at Tanhu station in Hangzhou Bay (Table 2; Fig. 6b). This longshore variation in SSC is rather unique, and is attributable to the varying influence of tidal hydrodynamics and to the "turbidity diluting" effects of river discharge and water from the open sea, as both of these water bodies have lower SSC than the area within the turbidity maximum. The annual average tidal range in 2009 increased from $2.6 \mathrm{~m}$ at Sheshan to $3.4 \mathrm{~m}$ at Tanhu (Fig. 6b). It is well known that bed shear stress is proportional to the square of flow velocity and that tidal flow velocity is proportional to tidal range. Accordingly, the tide-induced bed shear stress at Tanhu should be $71 \%$ greater than that at Sheshan. In fact, the measured difference in SSC is $203 \%$, probably reflecting the fact that Tanhu station is less influenced by the "turbidity diluting" effect of Yangtze discharge and of water from the open sea (Fig. 1b).

\section{Importance of Tides in Controlling Short-Term Variations} in SSC in the Yangtze Estuary and Adjacent Coastal Waters

In the present study area, tides seem to be more important than waves in controlling short-term (less than monthly scale) variations in SSC. For instance, based on twicedaily observations in 2009 at Dajishan station, the correlation coefficient between SSC and the square of tidal range was significantly greater than that between SSC and the square of wave height (Appendix Table 3). Dajishan station is macrotidal, has a $0.9-\mathrm{m}$ mean significant wave height, and has a $10-\mathrm{m}$ water depth. Measurable wave-bottom interaction does not occur until $d<0.25 L$ (where $d$ is water depth and $L$ is wavelength) (Hallermeier 1980). Based on the wellknown equation $L=g T^{2} / 2 \pi$ (where $T$ is wave period), the average wavelength at Dajishan would be $21 \mathrm{~m}$. Thus, normal waves do not interact with the bed when the water depth is greater than $5 \mathrm{~m}$ (or $>0.25 L$ ). This conclusion is mainly applicable to fair-weather conditions. During episodic storms, wave-induced seabed shear stress can be significantly increased and sediment resuspension may occur in water depths of up to $20 \mathrm{~m}$; however, such extreme events are relatively rare. Although wind-driven waves are important in controlling bed shear stress and SSC in the exposed intertidal wetland of the Yangtze Delta (Shi et al. 2012), the 


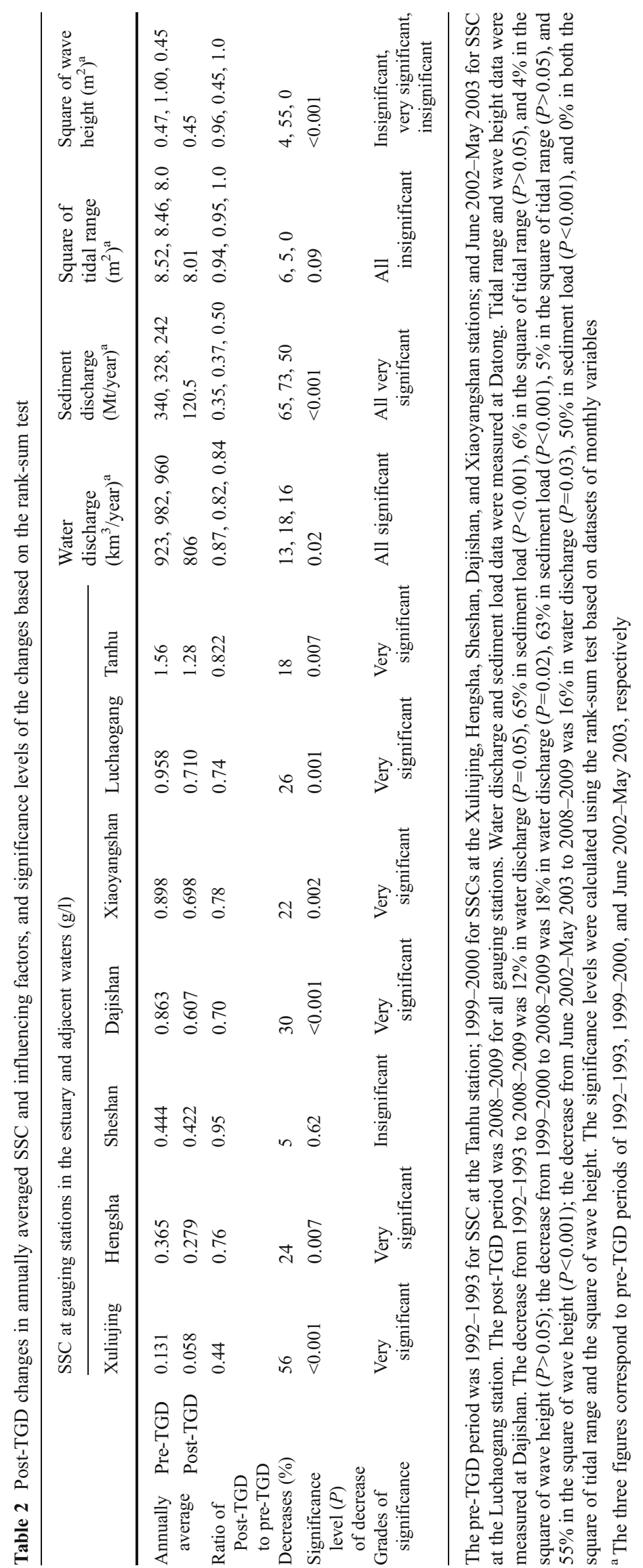


Table 3 Results of the Mann-Kendall test for temporal trends in SSC, tidal range, and wave height at Xiaoyangshan gauging station, and SSC, suspended sediment discharge, and water discharge at Datong, based on annually averaged values for 1998-2009

\begin{tabular}{|c|c|c|c|c|c|c|}
\hline & \multicolumn{3}{|c|}{ Xiaoyangshan station in the coastal water } & \multicolumn{3}{|c|}{ Datong station in the lower Yangtze River } \\
\hline & $\mathrm{SSC}$ & $\begin{array}{l}\text { Square of tidal } \\
\text { range }\end{array}$ & $\begin{array}{l}\text { Square of wave } \\
\text { height }\end{array}$ & $\mathrm{SSC}$ & $\begin{array}{l}\text { Suspended sediment } \\
\text { discharge }\end{array}$ & $\begin{array}{l}\text { Water } \\
\text { discharge }\end{array}$ \\
\hline \multicolumn{7}{|c|}{ Annual averages in $1998-2009$} \\
\hline$Z$ & -2.12 & -2.35 & -2.20 & -3.22 & -3.64 & -2.82 \\
\hline$P$ & 0.009 & 0.005 & 0.007 & $<0.001$ & $<0.001$ & 0.001 \\
\hline $\begin{array}{l}\text { Grades of } \\
\text { significance }\end{array}$ & Very significant & Very significant & Very significant & Very significant & Very significant & Very significan \\
\hline \multicolumn{7}{|c|}{3 -year running averages in 1998-2009 } \\
\hline$Z$ & -2.65 & 0.39 & -0.57 & -2.27 & -2.27 & -1.89 \\
\hline$P$ & 0.002 & 0.17 & 0.14 & 0.006 & 0.006 & 0.02 \\
\hline $\begin{array}{l}\text { Grades of } \\
\text { significance }\end{array}$ & Very significant & Insignificant & Insignificant & Very significant & Very significant & Significant \\
\hline
\end{tabular}

Positive and negative values of $Z$ (the standardized test statistic) indicate increasing and decreasing trends, respectively (Yang et al. 2010 and references therein)

area of exposed intertidal wetland is very small in comparison with the extensive estuarine and adjacent coastal waters (Fig. 1b). In summary, tides appear to generally play the dominant role in sediment resuspension in the Yangtze Estuary and adjacent coastal waters.

Controls on the Seasonal Cyclicity of Surface SSC in the Yangtze Estuary and Adjacent Coastal Waters

In the lower Yangtze Estuary and adjacent coastal waters, surface SSC is significantly lower in summer than in winter (Fig. 4), contrary to the seasonal cyclicity of river SSC at Datong Station (Yang et al. 2002; see also Fig. 2). It may seem counterintuitive that surface SSC should be highest during the winter months when fluvial sediment delivery is lowest (Fig. 2), but there are three points that explain this observation. First, the combination of low freshwater discharge and frequent winter storms results in a well-mixed water column in which bottom sediment is readily resuspended. In contrast, the presence of a freshwater lens during the high-discharge summer months leads to stratified conditions under which the little bottom suspension that occurs is not translated to surface waters (Milliman et al. 1984). Second, because the river SSC is less than the SSC of the estuarine and coastal waters (Fig. 5), the river discharge has a "turbidity diluting" effect that is greater in summer than in winter. Third, energetic wintertime winds increase the flow of the longshore China Coastal Current that carries highly turbid water from the Jiangsu coast southward; in contrast, the summertime northward longshore current carries less turbid water from the Zhejiang coast (Yang 1997). The results of a statistical analysis suggest that the "turbidity diluting" effect of river discharge is a dominant factor controlling the seasonal cyclicity of SSC in the lower Yangtze Estuary and adjacent coastal waters (Appendix Section 2.2).

Surface SSC in the Yangtze Estuary in Response to Decreasing Fluvial Sediment Flux

In recent decades, the transfer of suspended sediment to the sea from many of the world's rivers has drastically decreased as a result of human activities, primarily the construction of dams and irrigation (e.g., Dai et al. 2009; Meade and Moody 2010; Milliman and Farnsworth 2011, and references therein), thereby influencing the rivers' deltas (e.g., Syvitski et al. 2009; Yang et al. 2011 and references therein).

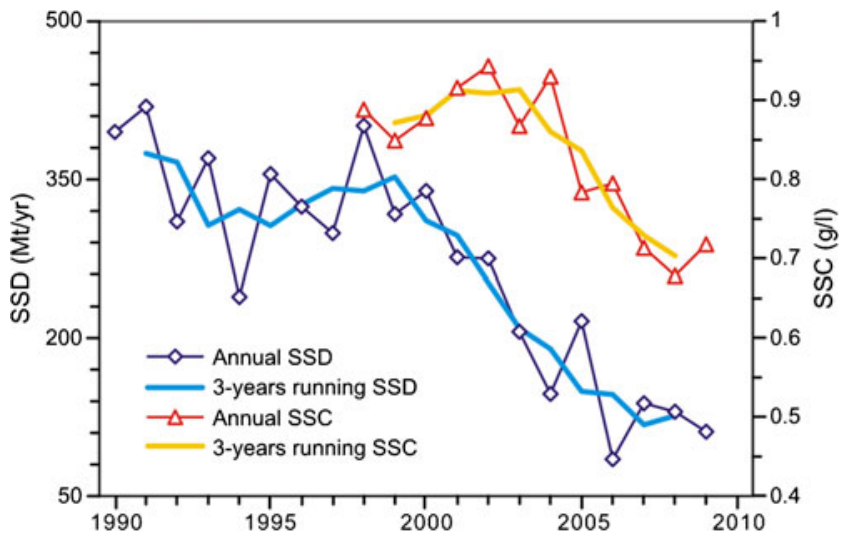

Fig. 7 Time series of annual surface suspended sediment concentration (SSC) at Xiaoyangshan and suspended sediment discharge (SSD) at Datong 
The response of SSC in estuarine and adjacent waters to human activities, however, has seldom been addressed (Schoellhamer 2011), probably due to a lack of adequate datasets. In the present study, annually averaged SSCs derived from twice-daily data measured at multiple gauging stations during the period 1992-2009 show an overall significant decline (Table 2 and Fig. 7).

Annually averaged SSC data have the advantage of smoothing tidal (daily), spring-neap, and seasonal fluctuations. Based on the annually averaged data, from the preTGD to post-TGD periods, the SSC in the Yangtze Estuary and adjacent coastal waters showed highly significant trends except at the Sheshan gauging station (Table 2). The riverine sediment load at Datong showed a highly significant decreasing trend, water discharge at Datong showed a significant decreasing trend, and the square of tidal range showed an insignificant decrease at Dajishan (0-6\%). Although the decrease in the square of wave height was statistically significant from pre-TGD 1999-2000 to post-TGD 20082009, it was insignificant from pre-TGD 1992-1993 to postTGD 2008-2009 and from pre-TGD June 2002-May 2003 to post-TGD 2008-2009 (Table 2). Between 1998 and 2009, the coastal SSC (at Xiaoyangshan) and influencing factors all showed significant decreasing trends (Table 3). However, for the 3-year-running-mean series over 2002-2009, the coastal SSC (at Xiaoyangshan) and the influencing factors of sediment load and water discharge at Datong showed significant decreasing trends, whereas the influencing factors of tides and waves did not (Table 3). That is, decreased estuarine and coastal SSC, based on a comparison between different periods, corresponded to significant decreases in riverine sediment load, but only some of the decreases corresponded to significant decreases in coastal hydrodynamics. Thus, although the decrease in annually averaged surface SSC in the estuarine and coastal waters has resulted from multiple influences, the major cause is undoubtedly the drastic decline in suspended sediment load from the Yangtze.

Even though SSC at Datong before and after closure of the TGD has shown a seasonal increase with river flow $(\mathrm{Xu}$ and Milliman 2009), SSC at Datong is still much lower than the SSC resuspended in coastal waters. Consequently, the additional SSC passing Datong during the period of seasonally high river flow does not compensate for the corresponding enhancement of the coastal dilution effect. Regarding the contribution of long-term changes in water discharge, if river discharge had not decreased from the preto post-TGD periods (which occurred mainly due to reduced precipitation in the Yangtze River basin), SSC in the estuary and adjacent waters presumably would have shown a smaller decrease because of the "turbidity diluting" effect of the river discharge, as shown above. The observed changes in SSC at and around the sampling sites cannot be simply explained by human activity.
Tidal hydrodynamics have changed little from the preTGD to post-TGD periods (Table 2). Although the decreasing trend in the square of tidal range observed for 1998-2009 was statistically significant, the square of tidal range decreased by only $5 \%$ (based on a regression formula), much less than the corresponding decrease in SSC (23\%) at Xiaoyangshan. Although wave energy has significantly decreased over the postTGD period (2008-2009) compared with the pre-TGD period (1999-2000; Table 2), it appears to have been a minor contributor to the decrease in estuarine and coastal SSC, considering the water depth of the gauging stations was greater than $5 \mathrm{~m}$ (Fig. 1b; Table 1). As shown above, normal waves are unable to disturb the seabed at this water depth. Furthermore, for the period 2002-2009, when both the 3-year running mean of SSC at Xiaoyangshan (Fig. 7) and the sediment load at Datong showed significant decreases, tidal and wave hydrodynamics at Xiaoyangshan did not show a significant decrease (Table 3). Thus, the long-term (decreasing) trend in SSC in the Yangtze Estuary and adjacent coastal waters is attributed mainly to a reduction in riverine suspended sediment supply. In the approaching decades, sediment supply from the Yangtze River is expected to further decrease following the construction of additional large dams (Yang et al. 2011). While erosion of the subaqueous delta is expected to continue, the rate of erosion will probably slow as a result of previous erosion. Under these influences, the SSC in the Yangtze Estuary and adjacent coastal waters will most probably continue to fall.

The 20-30\% decrease in SSC at most gauging stations in the Yangtze Estuary and adjacent waters is less than the 55\% decrease observed at Datong, except for the landward-most station, Xuliujing (Table 2). The similarity between Datong and Xuliujing suggests that no significant erosion or deposition has occurred along the reaches between these two sites (Yang et al. 2011). The de-coupling between SSC and sediment discharge is probably attributable to erosion of the subaqueous delta, which has experienced erosion rates of 100-150 Mt/year since the closure of the TGD in 2003 (Yang et al. 2011), similar to the rate of SSD measured at Datong in 2008-2009 (121 Mt/year; Fig. 7). This erosion rate represents about half of the reduction in SSD at Datong between the pre- and post-TGD periods (i.e., $207 \mathrm{Mt} / \mathrm{year}$; Table 2). Resuspension of sediment eroded from the subaqueous delta has partly offset the decline in suspended sediment from the Yangtze River, and has slowed the decrease in SSC in the lower Yangtze Estuary and adjacent waters. The smallest (statistically insignificant) reduction in SSC at Sheshan probably reflected particularly severe erosion at this site (Yang et al. 2011). Interestingly, there was a 3-4-year time lag between the decrease in SSC in coastal waters (e.g., at Xiaoyangshan Station) and the dramatic decrease in sediment discharge at Datong after closure of the TGD (Fig. 7). This time lag may indicate that erosion of 
the subaqueous delta was initially rapid (because the eroded material was fresh deposits) but slowed over time as older deposits (with a lower water content) were exposed, and the erosion was initially adequate to compensate for the decrease in supply of riverine suspended sediment.

The decrease in SSC in the Yangtze Estuary and adjacent coastal waters has important ecological and environmental consequences. The coastal waters off the Yangtze estuary and in Hangzhou Bay are one of the world's largest fisheries. A decrease in turbidity would probably increase the euphotic depth and thereby enhance primary production. On the other hand, a decrease in SSC would probably reduce the ability of suspended sediment to contain contaminants, leaving them in the water column to ultimately be absorbed by marine organisms. A decline in SSC in the Yangtze Estuary and adjacent coastal waters would also reduce the suspended sediment delivery southward to the Zhejiang Coast and onshore to the intertidal wetland, resulting in reduced deposition, perhaps erosion, in these areas.

\section{Conclusions}

We observed significant spatial variations in SSC in the Yangtze Estuary and adjacent coastal waters. The annually averaged SSC of surface seawater (in 2009) varied from $0.058 \mathrm{~g} / 1$ at the upstream limit of the estuary to $\sim 0.6 \mathrm{~g} / 1$ at the mouth-bar area $(110 \mathrm{~km}$ downstream of the upstream limit), falling again to $0.057 \mathrm{~g} / 1$ at the seaward limit of fresh water diffusion $(80 \mathrm{~km}$ from the mouth of the Yangtze Estuary). This cross-shore variation revealed the existence of an estuarine turbidity maximum, because of stronger tides and shallower water depths at the mouth-bar area, which results in the resuspension of sediment through the combined influence of tidal currents and waves, and because of the sediment trapping effect of salinity fronts at the mouth-bar area. A longshore, increasing trend in SSC from the Yangtze mouth to inner Hangzhou Bay is attributed to higher tidal hydrodynamic forces and the reduced influence of discharge from the Yangtze River, which diluted the concentration of sediment in the estuarine and coastal waters.

For all gauging stations, daily SSC showed a spring-neap tidal cyclicity. The regularity of these cycles was clearer at stations more strongly influenced by tides (i.e., those with a larger tidal range, a greater water depth, and located farthest from fluvial influences) relative to those more strongly influenced by waves and river discharge.

In the lower Yangtze Estuary and adjacent coastal waters, surface SSC showed a significant seasonality, with SSC in winter being two to four times higher than in summer. This seasonality is attributed mainly to the influence of dilution by river discharge, which was several times higher in summer than in winter.
The annual average surface SSC in the Yangtze Estuary and adjacent coastal waters has shown a decreasing trend since the closure of the TGD. Over this period, SSC at the upstream limit of the Yangtze Estuary (at Xuliujing station) has decreased by the same amount (55\%) as at Datong (500 km upstream). For downstream stations, changes in SSC over this period (5-30\% decrease, $21 \%$ on average) were less than that at Datong. The smallest and statistically insignificant decrease $(5 \%)$ in SSC occurred at the delta front, where severe erosion was observed. There was a 3-4-year time lag between the decrease in coastal SSC and the recent decrease in SSD at Datong. This de-coupling is attributed mainly to severe erosion of the subaqueous delta, compensating for the decrease in the supply of riverine suspended sediment.

SSC in the Yangtze Estuary and adjacent coastal waters is expected to continue to decrease in the future because suspended sediment load in the Yangtze River will be further decreased by the construction of new dams in the Yangtze basin, and erosion of the subaqueous delta is expected to slow. The decrease in SSC has important ecological, chemical, and geomorphological consequences for the present study area and for the East China Sea, thereby warranting further studies.

Acknowledgments This study was funded by the Natural Science Foundation of China (41130856), the Ministry of Science and Technology of China (2010CB951202), and NSFC for Innovation Team (41021064). Ms. Ying Cui and Ms. Ya-Juan Li are thanked for their assistance with experiment to remove the organic fraction (by loss-onignition) of suspended sediments. Two anonymous reviewers and the associate editor and Editor Dr. James Cloern are thanked for their comments and suggestions, which were helpful in improving an earlier version of this paper.

Open Access This article is distributed under the terms of the Creative Commons Attribution License which permits any use, distribution, and reproduction in any medium, provided the original author(s) and the source are credited.

\section{References}

Chen, J.Y., H.F. Zhu, Y.F. Dong, and J.M. Sun. 1985. Development of the Changjiang estuary and its submerged delta. Continental Shelf Research 4(1-2): 47-56.

Chen, S.L., G.A. Zhang, S.L. Yang, and J.Z. Shi. 2006. Temporal variations of fine suspended sediment concentration in the Changjiang River estuary and adjacent coastal waters, China. Journal of Hydrology 331: 137-145.

Dai, S.B., S.L. Yang, and M. Li. 2009. Sharp decrease in suspended sediment supply from China's rivers to the sea: anthropogenic and natural causes. Hydrological Sciences-Journal-des Sciences Hydrologiques 54(1): 135-146.

El-Asmar, H.M., and K. White. 2002. Change in coastal sediment transport processes due to construction of New Damietta Harbour, Nile Delta, Egypt. Coastal Engineering 46: 127-138.

Group of Shanghai Coastal Comprehensive Investigation (GSCCI). 1988. Report of the shanghai coastal comprehensive investigation. Shanghai: Shanghai Scientific and Technologic Publisher. 
Hallermeier, R. 1980. Sand motion initiation by waves: two asymptotes. Journal of the Waterway Port Coastal and Ocean Division 106(3): 299-318.

Hirsch, R.M., Helsel, D. R., Cohn, T.A., \& Gilroy, E.J. (1992). Statistical analysis of hydrologic data. In: D.R. Maidment (Ed.), Handbook of hydrology (pp. 17.21-17.23). Columbus: McGraw-Hill

Hu, B.Q., Z.S. Yang, H.J. Wang, X.X. Sun, N.S. Bi, and G.G. Li. 2009. Sedimentation in the three gorges dam and the future trend of Changjiang (Yangtze River) sediment flux to the sea. Hydrology and Earth System Sciences 13: 2253-2264.

Liu, J.P., A.C. Li, K.H. Xu, D.M. Velozzi, Z.S. Yang, J.D. Milliman, and D.J. DeMaster. 2006. Sedimentary features of the Yangtze River-derived along-shelf clinoform deposit in the East China Sea. Continental Shelf Research 26: 2141-2156.

Meade, R.H., and J.A. Moody. 2010. Causes for the decline of suspended-sediment discharge in the Mississippi River system, 1940-2007. Hydrological Processes 24: 35-49. doi:10.1002/ hyp. 7477.

Milliman, J.D., Y. Hsueh, D.X. Hu, D.J. Paskinski, H.T. Shen, Z.S. Yang, and P. Hacker. 1984. Tidal phase control of sediment discharge from the Yangtze River. Estuarine, Coastal and Shelf Science 19: 119-128.

Milliman, J.D., H.T. Shen, Z.S. Yang, and R.H. Meade. 1985. Transport and deposition of river sediment in the Changjiang Estuary and adjacent continental shelf. Continental Shelf Research 4: 37-45.

Milliman, J.D., and K.L. Farnsworth. 2011. River discharge to the coastal ocean: A global synthesis. Cambridge University Press, 384 p.

Orton, P.M., and G.C. Kineke. 2001. Comparing calculated and observed vertical suspended-sediment distribution from a Hudson River estuary turbidity maximum. Estuarine, Coastal and Shelf Science 52: 401-410.

Schoellhamer, D.H. 2011. Sudden clearing of estuarine waters upon crossing the threshold from transport to supply regulation of sediment transport as an erodible sediment pool is depleted: San Francisco Bay, 1999. Estuaries and Coasts 34: 885-899.

Schoellhamer, D.H., T.E. Mumley, and J.E. Leatherbarrow. 2007. Suspended sediment and sediment-associated contaminants in San Francisco Bay. Environmental Research 105: 119-131.

Shi, Z., and R. Kirby. 2003. Observations of fine suspended sediment processes in the turbidity maximum at the North Passage of the Changjiang Estuary, China. Journal of Coastal Research 19(3): 529-540.

Shi, B.W., S.L. Yang, Y.P. Wang, and T. Bouma. 2012. Sediment dynamic processes associated with combined current-wave action over an exposed tidal wetland, Yangtze Estuary. Geomorphology 138: 380-389. doi:10.1016/j.geomorph.2011.10.004.
Singh, M., I.B. Singh, and G. Müller. 2007. Sediment characteristics and transportation dynamics of the Ganga River. Geomorphology 86: $144-175$.

Syvitski, J.P.M., A.J. Kettner, I. Overeem, E.W.H. Hutton, M.T. Hannon, G.R. Brakenridge, C.J. Vörösmarty, Y. Saito, L. Giosan, and R.J. Nicholls. 2009. Sinking deltas due to human activities. Nature Geoscience 2: 681-686.

Uncle, R.J., and J.A. Stephens. 2010. Turbidity and sediment transport in a muddy sub-estuary. Estuarine, Coastal and Shelf Science 87: $213-224$.

Xu, K.H., and J.D. Milliman. 2009. Seasonal variations of sediment discharge from the Yangtze River before and after impoundment of the Three Gorges Dam. Geomorphology 104(3-4): 276-283.

Yang, S.L. 1997. Multi-factor analysis of the annually cyclic erosiondeposition of the Changjiang River delta. Acta Geographica Sinica 52(2): 123-130 (in Chinese with an English abstract).

Yang, S.L., Q.Y. Zhao, and I.M. Belkin. 2002. Temporal variation in the sediment load of the Yangtze River and the influences of the human activities. Journal of Hydrology 263: 56-71.

Yang, S.L., I.M. Belkin, A.I. Belkina, Q.Y. Zhao, J. Zhu, and P.X. Ding. 2003. Delta response to decline in sediment supply from the Yangtze River: evidence of the recent four decades and expectations for the next half-century. Estuarine, Coastal and Shelf Science 57: 589-599.

Yang, S.L., J. Zhang, and J. Zhu. 2004. Response of suspended sediment concentration to tidal dynamics at a site inside the mouth of an inlet: Jiaozhou Bay (China). Hydrology and Earth System Sciences 8(2): 170-182.

Yang, S.L., J. Zhang, and X.J. Xu. 2007. Influence of the Three Gorges Dam on downstream delivery of sediment and its environmental implications, Yangtze River. Geophysical Research Letters 34: L10401. doi:10.1029/2007g1029472.

Yang, S.L., Z. Liu, S.B. Dai, Z.X. Gao, J. Zhang, H.J. Wang, X.X. Luo, C.S. Wu, and Z. Zhang. 2010. Temporal variations in water resources in the Yangtze River (Changjiang) over the Industrial Period, based on reconstruction of missing monthly discharges. Water Resources Research 46: W10516. doi:10.1029/2009WR008589.

Yang, S.L., J.D. Milliman, P. Li, and K.H. Xu. 2011. 50,000 dams later: erosion of the Yangtze River and its delta. Global and Planetary Change 75: 14-20.

Zhao, C.H., Z.H. Zhu, and D.Z. Zhou. 2000. Worldwide rivers and dams. Beijing: China Water Conservancy and Hydroelectricity Press (in Chinese).

Zheng, L.Y., C.S. Chen, and F.Y. Zhang. 2004. Development of water quality model in the Satilla River Estuary, Georgia. Ecological Modelling 178: 457-482. 